https://doi.org/10.24316/prometeica.v0i17.231

\title{
CONTATO (1997): A IMAGINAÇÃO E O CONHECIMENTO CIENTÍFICO
}

\author{
CONTACT (1997): IMAGINATION AND SCIENTIFIC KNOWLEDGE
}

Ivy Judensnaider

(Doutoranda no PECIM-Unicamp e docente na UNIP - Universidade Paulista), ivynaider.unicamp@gmail.com

\author{
Fernando Santiago dos Santos \\ (Professor Associado do Instituto Federal \\ de Educação, Ciência e Tecnologia de São Paulo, campus São Roque \\ e Professor Colaborador do PECIM-Unicamp) \\ fernandoss@ifsp.edu.br
}

Recibido: 07/05/2018

Aprobado: 10/06/2018

\begin{abstract}
RESUMO
O "fazer científico" moderno pauta-se, invariavelmente, em um esquema procedimental que se articula à observação e à experimentação, negando formas de conhecimento que não atendam a seus princípios epistemológicos e de racionalidade metodológica. Criação e imaginação são campos raramente discutidos entre a comunidade científica, sendo, até, considerados inadequados. A crise da pós-modernidade coloca em xeque, até certo ponto, esta hegemonia da racionalidade e do conhecimento matematizável, coluna de sustentação da abstração dos fenômenos da natureza. Propomo-nos a discutir, com base no filme Contato (1997), de Zemeckis, que a imaginação e a experiência pessoal da protagonista, a cientista Ellie, podem ser elementos importantes - e por que não fundamentais? - da construção do conhecimento científico. A narrativa e a trama desta obra fílmica fazem-nos refletir sobre três argumentos plausíveis: prova da mentira, prova da verdade e prova da impossibilidade. Afinal, faz-se ciência somente com base em fatos observáveis, ou também é possível fazer ciência com base na imaginação? Este artigo tenta discutir esta possibilidade.
\end{abstract}

Palavras-chave: filme de ficção científica, ciência moderna, conhecimento científico.

\section{ABSTRACT}

The modern scientific approach invariably resides upon a procedural scheme that is articulated with observation and experimentation, commonly denying knowledge buildup not subjected to its epistemological and methodological rationality. The scientific community seldom discusses creation and imagination in science, being these attributes considered inappropriate. The post-modernity crisis challenges, to a certain extent, the hegemony of rationality and mathematically-based knowledge, which is the sustaining column for natural phenomena abstraction. We propose to debate, based on Zemeckis' movie - Contact (1997) -, that its protagonist, the scientist Ellie, brings us essential (and why not fundamental?) elements for scientific knowledge buildup, that is, imagination and personal experience. Both the narrative and the plot of this film work drive us into a reflection of three plausible arguments: proof of the lie, proof of truth, and proof of impossibility. After all, is science made only on the track of observable facts, or is it also built from imagination? The present article tries to discuss such a possibility. 
Keywords: scientific fiction movie, modern science, scientific knowledge.

\section{Introdução}

Em Contato (1997), o discurso científico-ficcional produzido pelo cinema narra a trajetória de uma cientista que produz um discurso a respeito do qual não se pode afirmar sua origem - se gerado pela imaginação formal ou pela imaginação criadora -, mas que abre novas possibilidades de apreensão da realidade e oportunidades para a discussão da importância epistemológica dos processos da imaginação e da criação na construção da ciência. Como filme de ficção, é criação sem compromisso com a realidade, mas que produz um discurso com força de verdade por meio de uma linguagem que dá origem a novos mundos que se alimentam do real e emulam o real, de forma lógica e racional, "livre de diferentes manifestos, sejam epistemológicos, filosóficos, sociológicos e/ou científicos" (Gomes-Maluf e Souza, 2008, p. 275). Complementando este raciocínio sobre a ficção científica e sobre seus mitos assim apresentados, também podemos citar Atlan (1994, p. 286): “(...) a ambiguidade do indizível que, no entanto, se diz, daquilo que é apenas implícito, mas que explicitamos largamente, é claramente suspensa, pois o caráter de verdade daquilo que assim se diz é imediatamente eliminado, sem deixar lugar a qualquer perigo de ser tomado como objeto de crença. Esta complementaridade só pode ser expressa de uma forma tal que não possamos acreditar nela; é precisamente esse o papel da ficção científica”.

Neste artigo, pretendemos investigar a narrativa científico-ficcional do filme Contato (1997). As questões a que nos propomos a responder são: (i) Quais são os caminhos que essa narrativa nos apresenta para o "fazer científico"?; e, (ii) Como o discurso fílmico coloca a imaginação como elemento-chave para a criação científica? Para respondermos a essas perguntas, deslocamo-nos, então, para o campo da fenomenologia: é a partir dessa perspectiva que as experiências narradas podem ser compreendidas, mesmo porque é dessa forma que a personagem principal consegue apreender os fenômenos que são colocados à sua frente. Percorrer os caminhos ocultos do pensamento, refazer os passos e desvendar os mistérios da experiência vivida constituem método fenomenológico que permite a "investigação daquilo que é genuinamente possível de ser descoberto e que está potencialmente presente, mas que nem sempre é visto através de procedimentos próprios e adequados. É o encontro com as coisas mesmas" (Lima, 2014, p. 13). Assim, propomo-nos a investigar a experiência intelectual e existencial no campo do conhecimento do fenômeno em si mesmo, que só pode ter sua essência desvelada no mesmo campo que o gestou: a imaginação.

\section{O filme Contato (1997) e as várias concepções sobre o “fazer científico”}

O filme Contato, de 1997, foi produzido e dirigido por Robert Zemeckis com base em obra homônima de Carl Sagan e Ann Druyan. Nele, Ellie ${ }^{3}$ (astrônoma especializada em radiotelescópios) consegue identificar sinais de inteligências extraterrestres emitidos de Vega, depois de anos de trabalho. Ellie é interpretada pela atriz norte-americana Jodie Foster, formada em Literatura pela Universidade de Yale e ganhadora de dois prêmios Oscar - em 1989, por seu trabalho em Os Acusados (1887) e, em 1992, pelo filme Silêncio dos Inocentes (1991). Os eventos narrados pelo filme têm lugar, supostamente, na década de 1990, já que o presidente Bill Clinton (no Governo de 1993 a 2001) interage com outros personagens por meio dos efeitos especiais.

Ellie desenvolveu uma bem-sucedida carreira acadêmica: é formada pelo MIT (Massachusetts Institute of Technology) e tem doutorado no CALTECH (California Institute of Technology). Seu local de trabalho é o SETI ${ }^{4}$, na estação de Arecibo, em Porto Rico. Para Ellie, sua pesquisa tem como fundamento uma proposição lógica: o ser humano não pode ser a única espécie existente em um universo tão infinito ${ }^{5}$.

Ao longo de sua jornada para provar a existência de inteligências extraterrestres, Ellie interage com dois homens: Palmer Joss (escritor e teólogo, cuja área de estudo inclui os efeitos da tecnologia no Terceiro Mundo) e Drumlin (seu cético e aético chefe). Embora preterida no processo inicial que seleciona o cientista que deverá viajar a Vega, é Ellie quem acaba sendo transportada na aeronave construída a partir 
das informações enviadas pelos extraterrestres. A viagem através de vários atalhos de tempo e espaço encerra-se quando Ellie chega a um lugar cujo cenário reproduz um antigo desenho feito por ela quando criança. Nesse lugar, o extraterrestre tem as feições de seu pai, já falecido. É ele o responsável por confirmar a Ellie a existência de inúmeras outras civilizações. Ao voltar para a Terra, e sem ter como provar as experiências pelas quais passou, o depoimento de Ellie é recebido com ceticismo. No entanto, o final do filme sugere que esse relato pode ser verdadeiro: embora as câmeras de televisão mostrassem que Ellie havia permanecido na nave apenas alguns momentos, a unidade de vídeo da máquina em que fora transportada havia funcionado durante 18 horas. Em outras palavras: embora não fosse possível confirmar a narrativa de Ellie, não havia como negá-la de maneira conclusiva.

O conflito entre Drumlin e Ellie envolve diferentes concepções a respeito do "fazer científico”. Drumlin materializa o cientista arrogante e manipulador: para ele, a ciência só alcança o conhecimento seguro quando pautada pela indução; assim, a experiência e a observação são os métodos mais adequados para a pesquisa científica. Mais: esta pesquisa é valorada em função dos resultados práticos preconizados pelos modelos tecnocráticos e positivistas (Winckler, 1999) e, de acordo com esta perspectiva, as sentenças que não atendem aos critérios de verificabilidade estão excluídas do campo da investigação científica (Gewandsznajder e Alves-Mazzoti, 1998).

Embora algumas correntes positivistas admitam a importância da imaginação e da criatividade quando da formulação hipotética, a postura de Drumlin é extremamente ortodoxa: em sua opinião, Ellie é brilhante e esforçada, mas obcecada por um campo de estudo que ele considera um suicídio profissional. Por isso, sua ironia em relação ao objeto de investigação de Ellie é explícita: para Drumlin, Ellie procura por "homenzinhos verdes" e apenas espera a ligação telefônica de um ET. Ao cortar as verbas da pesquisa de Ellie, Drumlin acredita estar fazendo um favor à colega: ela é uma cientista promissora demais para desperdiçar tempo com bobagens. De acordo com a concepção de ciência de Drumlin, a busca por outras formas de inteligência não merece o estatuto de trabalho científico. Inteligências extraterrestres não devem ser levadas a sério, nem mesmo como hipóteses de trabalho. Para ele, não há distinção entre o contexto da descoberta, associado ao processo criativo de formulação de hipóteses, e o contexto da justificação, concernente ao processo de validação dos achados e das construções teóricas. Para Drumlin, uma boa pesquisa científica não pode ter origem em algum processo lógico ou alheio às formas a partir das quais o cientista deve agir ou pensar. Em outras palavras, a descoberta e a justificação devem ter como base os mesmos princípios ontológicos e epistemológicos.

Ellie, em princípio, acredita no que pode ser comprovado por meio de evidências empíricas; é a ausência destas, inclusive, que a levam a não acreditar na existência de Deus. Complementarmente, porém, Ellie atribui à ciência a função de descobrir a finalidade da existência humana.

Ellie - Desde que eu me entendo por gente, eu venho procurando alguma coisa, uma razão do porquê estamos aqui, o que estamos fazendo, o que somos... E se essa é uma chance de descobrir mesmo que uma parte dessa resposta, eu acho que vale (Zemeckis, 1997, minuto 78).

Esta concepção finalista da ciência associa-se a um particular modo do fazer científico de Ellie. Assim, ao retornar de sua viagem e diante da desconfiança de todos, Ellie assume que a veracidade de seu relato só pode ser comprovada mediante termos que não os da validação empírica. Ellie admite que os cientistas, algumas vezes, trabalham a partir de construções teóricas que não foram - ou não podem ser - ratificadas pela experiência. Este é, por exemplo, o caso dos "buracos de minhoca", as pontes de Einstein-Rosen que ela imagina ter atravessado durante sua viagem.

No processo de construção do conhecimento, Ellie faz uso da imaginação para a compreensão do real; ela assume as limitações impostas pelo rigor da ciência, mas não se furta a debater as questões metafísicas associadas aos objetos e aos fenômenos investigados. Para Ellie, no contexto da descoberta, temas como inteligências extraterrestres são legítimos objetos da investigação científica. Por sua vez, no contexto da justificação, a imaginação e a criatividade são capazes de criar teorias justificáveis, corroboráveis ou não, refutáveis ou não: a descoberta é, também, trabalho científico ${ }^{6}$. 
Em Contato (1997), Ellie descobre novas formas de inteligência e outras civilizações. Mais: ela descobre que há esperança para a espécie humana e que somos capazes de construir um mundo melhor.

\section{Contato (1997): a imaginação como forma de acesso ao conhecimento sobre o espaço}

Buscando comparar as dimensões poéticas e científicas, Granger (1998, p. 7) definiu a imaginação como processo de criação de objetos num sistema simbólico que remete "a significações situadas para além dos conteúdos imediatos dados em sua percepção”. Por sua vez, a criação diria respeito aos objetos não preexistentes "enquanto tais na natureza ou no espírito do espectador" (idem). Para Granger (1998), a imaginação, essencial na criação poética, cumpriria apenas uma função auxiliar na criação científica; nesta, a representação do mundo sensível encarregar-se-ia de associar pensamento e objetos abstratos, priorizando os elementos formais.

Para o autor, na imaginação poética, e distintamente do que ocorre na imaginação científica, a ligação entre os objetos criados e o mundo sensível faz surgir emoções e sentimentos. Na criação poética, a imaginação cumpre a tarefa de subverter os dados captados pelos sentidos; na criação científica, em contrapartida, a imaginação coloca-se a serviço da representação dos dados sensíveis com o propósito de facilitar a apreensão das elaborações teóricas, especialmente daquelas que dependem de um elevado grau de abstração para a sua compreensão e para a sua aplicação (Granger, 1998). Ainda, é necessário considerar que, se a imaginação poética pode ou não se submeter a regras (as quais, arbitrárias ou não, funcionam como vetores para a criatividade), a submissão às normas ditadas pela lógica, na imaginação científica, é condição sine qua non.

Neste cenário, é natural que as necessárias vias racionais do conhecimento sejam percebidas como imperativas de uma ciência que pretende investigar as coisas naturalmente dadas, não inventadas. Para apreender o mundo que já está ali, é requisito que o processo de construção do conhecimento esteja associado ao possível, ao real, ao pensado como real. Em consequência, ao se assumir post hoc ergo propter hoc, fortalece-se a concepção equivocada de que o conhecimento científico - racional e produzido de acordo com as rígidas regras impostas pela comunidade científica - deva ser fruto de procedimentos também racionais e lógicos. Elege-se "um discurso como sendo o legítimo, o científico e o verdadeiro, [esquecendo que] (...) há outros discursos, outras maneiras também racionais de se falar da verdade” (Pessanha, 1993, p. 16). A perspectiva tradicional impõe, assim, o atributo de racionalidade e empiria como atributos indispensáveis do fazer científico, inclusive subestimando o papel da imaginação ${ }^{7}$.

Essa abordagem, que preconiza os parâmetros da racionalidade e do fazer científico livre de impurezas e subjetividade, no entanto, cria inúmeras dificuldades, especialmente no campo da reconstrução histórica da ciência: como compreender (ou categorizar) o trabalho de Leonardo da Vinci (1452-1519)? De onde poderiam ter surgido todos aqueles extraordinários e visionários artefatos mecânicos, hidráulicos e de engenharia, senão dos recantos mais recônditos de uma mente livre para imaginar? Segundo Rossi (2001, p, 76), a análise dos manuscritos e desenhos de Da Vinci nos coloca "diante de um limiar: isto é, estamos diante daqueles homens e daquele ambiente em que aquela aproximação e aquela compenetração (para nós impossível e ilusória) entre ciência e arte não só pareceram reais, mas se configuraram como reais”.

E, se Da Vinci for por demais polímata para que o tomemos como exemplo, vejamos o caso daquele que é considerado o paradigma da construção do conhecimento a partir da experiência e dos fatos: Galileu Galilei (1564-1642). Segundo Koyré (2006, p. 81), Galileu teria descoberto “montanhas na Lua, novos 'planetas' no céu, novas estrelas fixas em número tremendo, coisas que nenhum olho humano jamais havia visto e que nenhuma mente humana havia concebido antes”. Teria ele imaginado tudo isso antes mesmo de apontar o perspicullum para a Lua? Caso acreditasse que os olhos nus eram capazes de tudo enxergar, para que, então, construir algo que permitisse "transcender a limitação imposta pela natureza - ou por Deus - aos sentidos e ao conhecimento humano” (idem)? Para Stengers (1990), Koyré (um dos mais respeitados historiadores da ciência a investigar o trabalho do filósofo e inventor florentino) foi 
quem retirou Galileu do panteão dos cientistas que se curvaram aos fatos, atribuindo a ele outra posição de igual importância: distante da figura do sujeito que experimenta - e a partir daí, conclui - Galileu não teria se submetido aos fenômenos. De acordo com Koyré (2006, p. 20) ${ }^{8}$, "Galileu sabe a priori o que a experiência deve ser, e a rigor, ele não precisa fazer a experiência, ele a apresenta como se a tivesse feito”. Para Koyré, de forma distinta daquela realizada pelos seus predecessores, Galileu "funda a matemática justamente porque [...] não se submete aos fenômenos, e sim os julga em nome de uma ideia a priori, segundo a qual a essência dos fenômenos é matemática” (Stengers, 1990, p. 19).

Será essa a matematização da realidade que, posteriormente, receberá a contribuição decisiva de Descartes (1596- 1650): o cogito cartesiano é capaz de representar matematicamente a realidade, observadas de perto as regras da lógica e da correspondência analógica ${ }^{9}$. No entanto, vale ressaltar que isso tudo é representação por meio do uso da razão: mas representação, portanto fruto da imaginação e da intuição. Ou seja, é atividade criadora do pensamento racional, condicionada "pela inteligibilidade dos 'objetos' que são propostos à sua compreensão e a seus julgamentos” (Paty, 2001, p. 156), mas, ainda assim, exercício do pensamento e da criação. Supondo-se ou não as categorias apriorísticas de Kant de tempo e espaço, temos aqui uma experiência livre do pensamento. Afinal, o que é a matematização, senão “a passagem, por meio da criação, do particular ao geral” (Paty, 2001, p. 171)? O que é analogia, senão um "movimento do pensamento que escapa à simples comparação e à indução empirista, para 'inventar livremente”” (idem)?

Para Paty (2001), e tomando como base os pressupostos epistemológicos de Einstein e Poincaré, as ideias científicas são construídas de forma livre pelo pensamento: nem sempre induzidas de maneira lógica e compulsória com base nos dados da experiência, tampouco inscritas no pensamento de maneira inata ou a priori, elas teriam lugar no livre espaço da criação do trabalho científico e da descoberta. A invenção emergiria da atividade inconsciente e, sob o signo do livre arbítrio do pensamento, permitiria a combinação de ideias que, posteriormente, seriam oferecidas ao pensamento consciente. Ainda, os signos (as palavras) associados aos conceitos - perceptíveis aos sentidos e possíveis de serem reproduzidos - só se fariam necessários quando da comunicação, sendo dispensáveis quando do processo inconsciente do pensamento (Paty, 2001). Em consequência, as teorias, longe de explicarem o mundo natural dado (mas ainda não identificado), poderiam ser construídas no campo da criação e da invenção, inclusive na contramão daquilo que os sentidos e a experiência empírica admitiriam como prováveis ou possíveis (Paty, 2001) ${ }^{10}$.

Contato (1997) analisa as diferentes possibilidades de compreensão do mundo e "restitui à ciência uma dimensão poética esquecida nestes tempos de legitimação pela eficácia” (Winckler, 1999, p. 171). A imaginação de Ellie permite que ela acesse a poesia do cosmos e da existência humana. Da mesma forma como a beleza do evento celestial visto no exterior da nave só pode ser descrita em termos poéticos, sua experiência intelectual e existencial só pode ser compreendida no campo do conhecimento do fenômeno em si mesmo. Afinal, esta experiência "desorganiza toda a sua experiência anterior, estabelece um novo começo, que somente um poeta seria capaz de nomear pela imaginação” (Winckler, 1999, p. 174).

Não há evidências que corroborem o relato de Ellie; exceto pelos sinais emitidos a partir de Veja (i.e., os sinais da linguagem matemática que reproduzem os números primos), tampouco há como provar a existência de outras civilizações. No entanto, há o contato direto com o que ela supõe ser a essência da existência humana e, também, há o vivido que se torna o ponto de partida para a compreensão do universo infinito e de suas incomensuráveis possibilidades. Para ela, "resta a memória da experiência vivida e a vivacidade de seu relato, que somente a poesia, poder da imaginação, como diria Bachelard, poderia resgatar em sua inteireza e singularidade” (Winckler, 1999, p. 172); sobra o devaneio profundo que se entranha no próprio ser e se transforma em realidade, mesmo que primeva e remota.

O devaneio não conta histórias. Ou, pelo menos, há devaneios tão profundos, devaneios que nos ajudam a descer tão profundamente em nós mesmos que nos desembaraçam da nossa história. Libertam-nos do nosso nome. Devolvem-nos, essas solidões de hoje, às solidões primeiras. Essas solidões primeiras, essas solidões de criança, deixam em certas almas marcas indeléveis. Toda a vida é sensibilizada para o devaneio poético, para um devaneio que sabe o preço da solidão. A infância conhece a infelicidade pelos homens. Na solidão 
a criança pode acalmar seus sofrimentos. Ali ela se sente filha do cosmos, quando o mundo humano lhe deixa a paz (Bachelard, 1996, p. 94).

Por isso, diante das maravilhas com as quais se depara ao atravessar os túneis de tempo, Ellie conclui que apenas um poeta seria capaz de descrever sua experiência.

\begin{abstract}
Ellie - Estou passando por um tipo de túnel. Tem uma fonte luminosa à frente, azul e branca. Resíduo de radiação? É uma estrela, eu devo ter passado por um túnel do tempo. É Vega. Eu estou em outro túnel agora. Uma série deles. Isto parece com um tipo de sistema de trânsito, como o metrô. Tudo bem, tenho que continuar falando. É um triplo, não, um sistema quádruplo. É lindo. Deve ser outro túnel, muito mais violento. É um evento celestial. Não, não há palavras para descrever isso. Poesia. Deveriam ter mandado um poeta. É tão lindo, é tão lindo. Eu não fazia ideia. Eu não fazia ideia... eu não fazia ideia (Zemeckis, 1997, minuto 115).
\end{abstract}

Não há outra forma de representar o que Ellie viu, senão a da poesia. O fenômeno só pode ter sua essência desvelada no campo da imaginação, acionada como requisito para a sobrevivência, e que estabelece ordem e sentido ao que é experimentado (Winckler, 1999, p. 173). Por isso, a orfandade provoca o devaneio infantil de Ellie que faz emergir o desejo de acabar com a solidão. Para Bachelard (1996, p. 98), a alma que sonha é uma consciência de solidão e, na solidão feliz, a criança acessa o devaneio cósmico que nos mantém ligados ao mundo. Se o impossível é obstáculo intransponível, a imaginação criadora e a vontade resistem à realidade, colocando-se em oposição à materialidade do universo e das coisas (Silva, 2009, p. 4).

Outras formas de inteligências podem - e devem ser - encontradas. Para Ellie, esse propósito é concretizado quando ela chega ao lugar de onde foram transmitidos os sinais para a Terra, o mesmo lugar que, quando criança, idealizou. A imaginação - formal ou criativa - contempla as possibilidades que a realidade ignorou e o devaneio traz consigo a consciência de bem-estar. "Numa imagem cósmica, assim como numa imagem da nossa casa, estamos no bem-estar de um repouso" (Bachelard, 1996, p. 170), como se atingíssemos um estado de absoluta perfeição. Pensacola é como ela havia imaginado e quem fala sobre um futuro repleto de esperanças é seu pai: não é apenas a sua solidão que tem fim, mas a da espécie humana que viaja pelo imenso e infinito universo, buscando respostas para a própria existência. "De fato, nós e nossas máquinas apenas molhamos os pés no oceano cósmico que se estende para além da Terra” (Silva, 1999, p. 5).

Não há como provar, tampouco como negar: a imaginação de Ellie traz "a marca da subjetividade, estabelece[ndo] uma crítica contra o modo excessivamente racionalista e materialista de conceber o homem e o mundo" (Silva, 2009, p. 2). Não há sequer como tornar a narrativa crível do ponto de vista do tempo e do espaço; no entanto, os devaneios de Ellie têm força de verdade, têm seu curso legitimado nas profundezas do ser sem qualquer compromisso com a realidade e com a empiria. Por isso, ela assim se explica aos que a interrogam:

\footnotetext{
Ellie - Não posso provar, não posso explicar, mas tudo o que eu sou como ser humano, tudo me diz que foi real. Foi uma coisa maravilhosa, uma coisa que me mudou para sempre. Uma visão do universo que nos diz, inegavelmente, como todos nós somos pequenos e insignificantes, e como somos raros e preciosos. Uma visão que nos diz que pertencemos a uma coisa que é maior do que nós mesmos, e que não estamos, nenhum de nós está sozinho (Zemeckis, 1997, minuto 116).
}

São esses os termos por meios dos quais Ellie tenta, inutilmente, justificar seu relato. O que resta a Ellie é propor que a racionalidade e a experimentação dividam terreno com a imaginação, permitindo que esta alcance o que é inalcançável; em outras palavras, ela propõe que a imaginação organize cognitivamente o mundo, apesar e além dos dados imediatos (Gomes-Maluf e Souza, 2008). É por meio deste processo que Ellie torna cósmica a lembrança de um tempo remoto: na experiência vivida, estão todos os elementos do desenho feito quando era apenas uma criança, estão ali os seus sonhos de infância tornados realidade, está ali o seu pai garantindo que há um sentido maior na vida, está ali a resposta à pergunta sobre quem somos e qual o sentido da nossa existência. 


\section{Considerações Finais}

Para Atlan (1994), o trabalho de Sagan - inclusive a série e o livro Cosmos - não pode ser considerado científico: Sagan trabalha no terreno da ficção científica. Essa não é uma crítica solitária: para vários cientistas, Sagan teria incluído, no campo da ciência, temas como inteligência extraterrestre e fenômenos paranormais, confundindo, dessa forma, as esferas do cientificamente comprovado e da especulação descompromissada (Morrison, 2009). Curiosamente, esse cenário emula o embate entre Ellie e Drumlin no que diz respeito à escolha dos objetos e das hipóteses passíveis de teste e análise científica, e à elaboração de explicações para os fenômenos da natureza.

Ao retornar de sua viagem, os congressistas, os cientistas e a sociedade dizem à Ellie: "prove ser verdade”. Caso Ellie conduzisse sua abordagem nos termos popperianos, seria razoável que ela redarguisse, em sentido contrário: "provem-me ser mentira”. Afinal, embora sua viagem parecesse não ter acontecido, a unidade de vídeo de sua nave gravara sinais de estática durante 18 horas, o que coloca a corroboração e a refutação fora do alcance de Ellie e dos que a ela se opõem.

Contato (1997) nos sugere outra possibilidade: materializando o discurso científico-ficcional de Sagan, Ellie bem poderia ter proposto outro desafio aos que a interrogavam: "provem-me ser impossível”.

\section{Referências}

Atlan, H. (1994). Com Razão ou Sem Ela: Intercrítica da Ciência e do Mito. Lisboa: Piaget.

Bachelard, G. (1996). A poética do devaneio. Trad. Antônio de Pádua Danesi. Martins Fontes: São Paulo.

Gewandsznajder, F. \& Alves-Mazzotti, A. J. (1998). O método nas Ciências Naturais e Sociais. São Paulo: Pioneira.

Gomes-Maluf, M. \& Souza, A. (2008). A ficção científica e o ensino de ciências: o imaginário como formador do real e do racional. Ciência \& Educação (Bauru), 14(2), 271-282. Disponível em http://www.redalyc.org/html/2510/251019505006

Granger, G. G. (1998). Imaginação poética, imaginação científica. Discurso, (29), 7-14. Disponível em http://www.periodicos.usp.br/discurso/article/view/62635/65439

Koyré, A. (2006) Do mundo fechado ao universo infinito. Rio de Janeiro: Forense Universitária.

Lima, A. B. M. (Org.) (2014). Ensaios sobre fenomenologia: Husserl, Heidegger e Merleau-Ponty. Ilhéus: Editus.

Monteiro, R. H. (2007). Contato: Afinal, estamos sozinhos? In: Oliveira, B. J. de (Org.), História da Ciência no Cinema 2 - O Retorno (pp. 131-143). Brasília: CAPES; Belo Horizonte: Argvmentvm.

Morrison, D. (2009). Carl Sagan's Life and Legacy as Scientist, Teacher, and Skeptic. Skeptical Inquirer, 2007-11. Disponível em https://www.csicop.org/si/show/carl_sagans_life_and_legacy_as_scientist_teacher_and_skeptic/ \&q=carl+sagan+biography\&sa=X\&ei=3zUQUIjNNoam0AWf8IDABw\&ved=0CDIQFjAF

Paty, M. (2001). A criação científica segundo Poincaré e Einstein. Estudos Avançados, 15(41), 157-192. Disponível em http://www.scielo.br/pdf/ea/v15n41/v15n41a13.pdf

Pessanha, J. A. (1993). Filosofia e modernidade: racionalidade, imaginação e ética. Educação \& Realidade, 22 (1). Disponível em http://www.seer.ufrgs.br/educacaoerealidade/article/download/71454/40538 
Rossi, P. (2001). O nascimento da ciência moderna na Europa. Bauru: Edusc.

Sagan, C. (1996). Pálido ponto azul. São Paulo: Companhia das Letras.

Seti (2018). Our Scientists: Jill Tarter. Disponível em https://www.seti.org/users/jill-tarter

Silva, A. N. B. da (2009). Imaginação criadora e educação: considerações sobre o pensamento de Gaston Bachelard. Disponível em http://www.cchla.ufrn.br/humanidades2009/Anais/GT32/32.1.pdf

Silva, H. C. (1999). As imagens do espaço no filme Contato. Ciência e Ensino, 6, 5-10.

Skibba, R. (2017). Astrobiology: Hunting aliens. Nature, 546 (7660), 596. Disponível em https://www.nature.com/articles/546596a.pdf

Stengers, I. (1990) Quem tem medo da ciência? - ciências e poderes. Trad. Eloísa de Araújo Ribeiro. São Paulo: Siciliano.

Winckler, C. R. (1999) Imaginação, poder e ciência: considerações acerca do filme Contato Extraterrestre. Revista FAMECOS, 6(10), 171-175. Disponível em http://revistaseletronicas.pucrs.br/ojs/index.php/revistafamecos/article/view/3041/0

Zemeckis, R. (Dir.) (1997). Contato. Título original: Contact. Com Jodie Foster e Matthew McConaughey. DVD. Cor. 150 min. Warner-Bros Brasil.

\section{Notas}

${ }^{1}$ Doutoranda no PECIM-Unicamp e docente na UNIP (Universidade Paulista), ivynaider.unicamp@gmail.com.

${ }^{2}$ Professor Associado do Instituto Federal de Educação, Ciência e Tecnologia de São Paulo, câmpus São Roque e Professor Colaborador do PECIM-Unicamp, fernandoss@ifsp.edu.br.

${ }^{3}$ A personagem Ellie Arroway foi parcialmente inspirada em Jill Tarter (Skibba, 2017). Engenheira física pela Cornell University, com mestrado e doutorado pela University of California, Berkeley, Jill Tarter trabalhou no SETI e tem tido papel de destaque na busca de financiamentos privados para projetos científicos (Seti, 2018).

${ }^{4}$ O SETI é um programa de colaboração acadêmico-científica que busca sinais de inteligência extraterrestre por meio da análise de dados radiotelescópicos (Seti, 2018).

\footnotetext{
${ }^{5}$ Essa questão está longe de ter sido resolvida. Ainda nos dias de hoje, "tudo o que se disse sobre vida extraterrestre é mera especulação. Mas a Terra já foi considerada o centro do sistema solar e o centro do universo, a nossa galáxia era tida como a única... O desenvolvimento da astronomia tem mostrado que não ocupamos qualquer posição privilegiada no tempo e no espaço” (Monteiro, 2007, p. 142). Esta foi uma das crenças que Sagan defendeu com afinco: em Pálido ponto azul, o autor descreve a imensidão do universo em oposição ao nosso tamanho ínfimo. Nas suas palavras, “a Terra é um palco muito pequeno em uma imensa arena cósmica” (Sagan, 1996, p. 10).

${ }^{6}$ De forma alguma Ellie defende o anarquismo metodológico preconizado por Feyerabend. Segundo este, "se ensinam-se ciências, se ensina-se Galileu nas escolas secundárias, é preciso ensinar também a mitologia X, nem mais ou menos 'retórica', nem mais ou menos relativa a um contexto de referência indemonstrável. [...] Portanto, a educação deveria ser neutra em relação às ciências como ela o é hoje em dia em relação à religião” (Stengers, 1990, p. 21). Embora inclua alguns temas não ortodoxos no rol daqueles passíveis de investigação científica, Ellie sabe diferenciar ciência de não-ciência (ou, de algum modo, de pseudociência). Sua relação com experiências que não se submetem à empiria está mais próxima do espanto e da angústia do cientista diante das limitações impostas pela hegemonia metodológica da modernidade: “(...) chegamos ao século XX com essa angústia. É a angústia que o neopositivista expressa e que passa para todo mundo. A encruzilhada parece ser esta: ou a clareza, e aí a ciência no sentido mais pleno, o epistêmico no sentido mais luminoso, ou então a impossibilidade da clareza e, por que não, o obscurantismo, o emocionalismo, o simples arrepio, a simples intuição, questões que hoje estão voltando à moda com muita insistência” (Pessanha, 1993, p. 23). Ellie sabe (ou intui) que é possível fazer ciência sem que seja obrigatório “manter-se no nível da razão analítica e da prova coagente” (Pessanha, 1993, p. 26).
} 
${ }^{7}$ Segundo Pessanha (1993, p. 22), a ciência moderna amparou-se em dois grandes modelos científicos: o matemático e o indutivo. Mais do que apenas alimentar a produção científica, esses modelos também teriam o objetivo de alimentar “o próprio imaginário do homem a respeito da humanidade”.

${ }^{8}$ Para Stengers (1990), a leitura que Koyré faz de Galileu não está isenta de controvérsias. Embora admitindo a reduzida respeitabilidade de outro importante historiador da ciência, Pierre Duhem, Stengers acha relevante lembrar que, para este, Galileu não havia realizado nada que já não tivesse sido concretizado por qualquer outro filósofo medieval e escolástico. Duhem, físico francês e católico, defendeu, em oposição a Koyré, que a física de Galileu era, na verdade, de essência católica, e que já havia sido pensada pelos predecessores do filósofo florentino. Assim, o caso de Galileu não teria relação com a experiência, tampouco com a imaginação ou com a invenção: tratar-se-ia tão somente de um conhecimento cumulativo que, para formular as leis do movimento, só precisava de um “pequeno empurrão”.

${ }^{9}$ Para Paty (2001, p. 159), Descartes teria estabelecido o que, para ele, “deveriam ser as condições da inteligibilidade; elas incluíam as condições da invenção (que a seu ver eram sobretudo da ordem da descoberta), já que toda compreensão por parte de um sujeito é, em certa medida, reinvenção”. Segundo Pessanha (1993, p. 16), Descartes, “em meio às suas pesquisas, nas noites dos idos de 1660, começa a ter certos sonhos que o levam a uma espécie de êxtase intelectual. São sonhos de alumbramento, de luminescência, em que toda a pesquisa matemática de alguma forma se configura e se propõe diante dele. Descartes descobre que tudo pode ser explicado através de números. Na verdade, redescobre como ocidental uma premissa que vem da Antiguidade grega, sobretudo dos pitagóricos”.

${ }^{10}$ Assume-se, então, que o conhecimento científico vai além de seus conteúdos seguros, compreendendo, “em suas dimensões o próprio trabalho do pensamento que o estabelece” (Paty, 2001, p. 157). Em relação a Einstein, Paty (2001, p. 171), inclusive, conclui que "esse trabalho de criação utiliza o raciocínio (que não encerra apenas dedução, mas é também construtivo ao constituir os objetos) tanto quanto a intuição, termo pelo qual designamos aqui uma percepção (intelectual) sintética de um complexo de conceitos”. Ainda para este autor, "Inventar é ver [... e o] desenvolvimento dessa intuição permite a capacidade de inventar e de ser criador” (Paty, 2001, p. 175). Assim, será por meio da imaginação criativa que os objetos do pensamento se transformam em representações do mundo, importando, também, "saber como os elementos do conhecimento surgem com a novidade daquilo que, até então inexistente, é, num certo momento, inventado e criado” (idem, p. 183). 